\title{
EDUCADORA HENRIQUETA GALENO: TRAJETÓRIA DE UMA LITERATA FEMINISTA (1887-1964)
}

DOI: http://dx.doi.org/10.1590/2236-3459/75182

\author{
Lia Machado Fiuza Fialho' \\ 'Universidade Estadual do Ceará (Uece), Fortaleza/CE, Brasil \\ Évila Cristina Vasconcelos de Sál \\ "Universidade Estadual do Ceará (Uece), Fortaleza/CE, Brasil \\ $\cos 80$
}

\begin{abstract}
Resumo
Situada no campo da História da Educação, a pesquisa se debruça no estudo da vida de Henriqueta Galeno (1887-1964), uma educadora que atuou no cenário patriarcalista da primeira metade do século XX, na cidade de Fortaleza - Ceará. O objetivo foi biografar a professora Henriqueta Galeno com ênfase na sua formação educacional e inserção no movimento feminista. Por meio da pesquisa documental - jornais, revistas, relatórios, compêndios autobiográficos, obra póstuma -, constatou-se que Henriqueta: recebeu educação primária com professora particular; estudou no Colégio Imaculada Conceição e no Liceu do Ceará, em tempos que só ingressavam homens; foi a primeira aluna e professora do Liceu, após formar-se em Direito. Mesmo subjugada ao pai, tornou-se intelectual com expressiva participação no movimento feminista cearense, rompendo paradigmas culturais e problematizando dogmas sociais.

Palavras-chave: Henriqueta Galeno, História da Educação, biografia, feminismo.
\end{abstract}

\section{EDUCADORA HENRIQUETA GALENO: TRAYECTORIA DE UNA LITERATA FEMINISTA (1887-1964)}

\begin{abstract}
Resumen
Anclada en el campo de la Historia de la Educación, esta investigación se volcó al estúdio de Henriqueta Galeno (1887-1964), una educadora que actuó en el contexto patriarcal de la primera mitad del siglo XX, en la ciudad de Fortaleza - Ceará. Se intentó redactar la biografía de la profesora Henriqueta Galeno, con énfasis en su formación educacional y en su inserción en el movimiento feminista. Através de una búsqueda documental - periódicos, revistas, informes, compendios autobiográficos, obra póstuma, se constató que Henriqueta: recibió educación primaria con profesora particular; estudió en el Colegio Inmaculada Concepción y en el Liceo del Ceará en tiempos en los cuales el acceso a tales instituciones era restricto a los hombres; fue la primera alumna y profesora del Liceo tras graduarse em Derecho. Pese a estar subyugada a su padre, se convirtió en intelectual con expresiva participación en el movimiento feminista cearense, rompiendo paradigmas culturales y problematizando dogmas sociales.

Palabras clave: Henriqueta Galeno, Historia de la Educación, biografía, feminismo.
\end{abstract}




\title{
EDUCATOR HENRIQUETA GALENO: \\ TRAJECTORY OF A FEMINIST LITERATURE (1887-1964)
}

\begin{abstract}
Located in the field of History of Education, the research focuses on the study of the life of Henriqueta Galeno (1887-1964), an educator who worked in the patriarchal scenario of the first half of the 20th century, in the city of Fortaleza - Ceará. The objective was to biograph the teacher Henriqueta Galeno with emphasis in its educational formation andinsertion in the feminist movement. Through documentary research - newspapers, magazines, reports, autobiographical compendium, posthumous work -, it was found that Henriqueta: she received primary education with a private teacher; she studied at the Imaculada Conceição and at the Liceu do Ceará school, in times when only men entered; she was the first student and teacher of the Liceu school, after graduating in Law. Even subjugated to the father, she became an intellectual with an expressive participation in the feminist movement of Ceará, breaking cultural paradigms and problematizing social dogmas.

Keywords: Henriqueta Galeno, History of Education, Biography, Feminism.
\end{abstract}

\section{ÉDUCATRICE HENRIQUETA GALENO: TRAJECTOIRE D'UNE FEMME DE LETTRES FÉMINISTE (1887-1964)}

\section{Résumé}

Située dans le domaine de l'Histoire de l'Éducation, la recherche se penche sur l'étude de la vie de Henriqueta Galeno (1887-1964), une éducatrice qui a vécu dans la scène patriarcale de la première moitié du XXème siècle, dans la ville de Fortaleza - Ceará. L'Objectif de ce travail a été de faire la biographie de l'éducatrice Henriqueta Galeno en mettant l'accent sur sa formation éducative et son insertion dans le mouvement féministe. Au moyen d'une recherche documentaire - par des journaux, des magazines, des rapport, des recueils autobiographiques, des œuvres posthumes-, on a constaté que Galeno a reçu l'éducation primaire avec une professeur particulière; ensuite, elle a étudié à l'école Imaculada Conceição et dans le Liceu do Ceará, dans une époque où les seulement les hommes avaient accès aux études; elle a été la première étudiante et professeur du Liceu, après avoir eu sa licence en Droit. Même réprimée par son père, elle est devenue intellectuelle et a eu une forte participation dans le mouvement féministe cearense, en rompant des paradigmes culturels, et en problématisant des dogmes sociaux.

Mots-clés: Henriqueta Galeno, Histoire de l'éducation, biographie, féminisme. 


\section{Introdução}

A presente pesquisa versa sobre a biografia de Henriqueta Galeno; constitui uma investigação amparada teórico-metodologicamente na área de História da Educação. Henriqueta Galeno (1887-1964) galgou considerável inserção no mundo letrado através de suas participações em agremiações literárias e jornais, inclusive ocupando cadeira na Academia Cearense de Letras e dirigindo o Salão Juvenal Galeno ${ }^{1}$. Essa educadora seguiu caminhos diferentes daqueles trilhados pela maioria das mulheres fortalezenses do seu tempo, frequentando espaços destinados aos homens na sociedade patriarcalista do Ceará do século XIX e difundindo ideias feministas no primeiro quartel do século $X X$.

Docente, escritora, solteira e autônoma, a intelectual Henriqueta Galeno não atuou apenas na educação primária, sendo ativa também nos movimentos culturais e políticos da época, defendendo a tese de que a mulher deveria ter oportunidades de acesso às profissões na mesma proporção e com o mesmo reconhecimento que os homens. Ela ultrapassava o anseio pelo direito de voto e defendia a igualdade das mulheres aos homens em todas as esferas da vida política, econômica, intelectual, social e cultural.

O objetivo foi biografar a professora Henriqueta Galeno com ênfase na sua formação educacional e inserção no movimento feminista. Para alcançar esse escopo, delinearam-se objetivos específicos, quais sejam: 1) traçar o cenário histórico e social em que Henriqueta Galeno viveu: a cidade de Fortaleza nos fins do século XIX e início do XX, vinculando-o com a institucionalização da educação formal em Fortaleza; 2) caracterizar a trajetória de formação educacional e profissional de Henriqueta Galeno; e 3) compreender o ingresso de Henriqueta Galeno no universo intelectual, bem como no movimento feminista. Visa-se responder à seguinte inquietação: que formação educacional Henriqueta Galeno desenvolveu para conseguir ingressar como primeira professora no Liceu do Ceará e propagar ideais feministas, conquistando espaços antes somente ocupados por homens?

Para responder a essa inquietação, desenvolveu-se uma pesquisa documental, calcada na análise de: revistas - Revista da Academia Cearense de Letras (1977), Revista do Instituto Histórico e Geográfico do Ceará e Revista O Cruzeiro (1957) -, de jornais Jornal Correio do Ceará (1964) e Jornal Gazeta de Notícias (1931) -, de relatórios Relatório do Governador do Estado do Ceará (1919) e Relatório de Accioly (1899) -, do Diário Oficial do Estado do Ceará (1914), de Mensagem da Assembleia (1918), de uma autobiografia de Henriqueta Galeno (1986) e da obra de Henriqueta Galeno no Congresso Feminista (1932).

Ante o estudo já iniciado, defende-se como argumento que Henriqueta Galeno foi uma educadora, escritora e intelectual que teve importante papel na propagação do ideário feminista no Ceará da primeira metade do século XX. Docente, solteira e católica, Henriqueta Galeno não atuou apenas no mundo letrado e pedagógico, sendo também ativa

\footnotetext{
1 O Salão Juvenal Galeno, fundado em 1919, na residência de Juvenal Galeno - construída em 1888 na cidade de Fortaleza/CE - foi idealizado por Henriqueta Galeno para homenagear seu pai, o poeta de mesmo nome da instituição. (FIALHO; SÁ, 2016). Henriqueta Galeno dirigiu esse espaço, uma espécie de museu vivo, que atualmente se denomina Casa Juvenal Galeno. Nele, há um valioso acervo bibliográfico doado por Mozart Monteiro, a biblioteca do Juvenal Galeno - que juntos totalizam dezoito mil volumes - além de auditórios, salões, dentre outros espaços que possibilitam atividades culturais diversas. A Casa de Juvenal Galeno foi tombada em 2016 e hoje é um dos maiores centros da cultura cearense, mantido pela Secretaria da Cultura do Estado do Ceará (Secult).
} 
e pioneira ao defender concepções pessoais que se coadunavam com a ampliação da participação sociopolítica feminina, identificadas com sua participação nos principais movimentos culturais e políticos da época. Com sua inserção no mundo letrado, através de suas participações em agremiações literárias e jornais, percebe-se que a referida educadora seguiu caminhos diferentes daqueles trilhados pela maioria das mulheres fortalezenses do seu tempo, ampliando espaços destinados às mulheres e impulsionando reflexões às suas conterrâneas cearenses acerca de seu lugar na sociedade.

As discussões são pautadas na perspectiva da Nova História e nos estudos biográficos da História da Educação, fundamentando-se nos estudos de Bourdieu (1996), Foucault (1986), Le Goff (2010a, 2010b), Levi (1996), Machado (2010), Reis (2000), Rodrigues (2015), dentre outros. A narrativa biográfica de Henriqueta Galeno reconstitui sua história desde o seu nascimento, perpassando por seus percursos de formação - na educação primária, secundária e superior - e pelas significativas influências intelectuais de seu pai, o escritor Juvenal Galeno, e lançando luz para a formação intelectual e a difusão das ideias feministas no retorno ao Ceará, quando de sua participação no Segundo Congresso Internacional Feminista, após o falecimento de seu genitor.

\section{O gênero biográfico na História da Educação: o percurso metodológico}

Considerando que a pesquisa se propõe a desenvolver uma biografia, inserida no campo da História da Educação, referente à educadora Henriqueta Galeno, com ênfase na sua formação educacional e inserção no movimento feminista, faz-se necessário compreender a conceituação utilizada acerca da biografia, ou seja, do ato de biografar do ponto de vista da historiografia, bem como sua importância nos estudos das histórias de vida de educadoras.

Tal gênero de historiar foi relegado pelos Annales na primeira metade do século $\mathrm{XX}$, pelo fato do desprestígio em biografar "grandes vultos", outrora analisados e interpretados pelos metódicos da escola positivista "rankeana" oitocentista, sendo negligenciado pelo meio acadêmico. Como afirma Rodrigues (2015, p. 55): "A crítica ao tradicional modelo de história personalista, centrada na figura de heróis, mártires, gênios, sábios e santos, afastou os historiadores dos estudos biográficos por muito tempo". Novos olhares emergiram representados na terceira geração dos Annales, como foi, por exemplo, o caso de Le Goff (2010a, 2010b) ao biografar São Francisco de Assis e São Luís.

Distanciado do personalismo, apesar de os biografados serem de grande porte histórico, Le Goff (2010a, 2010b) ensejava dar visibilidade à micro-história, ao lançar luz às particularidades de vidas na interface com o contexto sócio-histórico e cultural, impulsionando os estudos biográficos tanto na academia como nos ambientes concernentes ao público leigo. O referido autor, com relação ao compêndio pertinente à biografia de São Luís, mostrou não apenas fatos lineares enaltecedores de tal personagem, fazendo também, de maneira crítica, um apanhado da vida de São Luís em consonância com toda a conjuntura histórica do tempo em que viveu o biografado, sua participação nas Cruzadas, os percursos de sua canonização, a organização da monarquia absolutista francesa. (RODRIGUES, 2015).

Desse modo, evidenciava-se a compreensão de que uma biografia não se restringia às particularidades de um indivíduo, dado que: 
A trama biográfica tem um sentido metonímico. Busca conhecer o todo pela parte. O todo é a sociedade da época vivida pelo personagem central e pelos sujeitos que com ele formaram a urdidura apresentada pelo narrador, na qual se deu a interatividade entre o personagem e o ambiente físico e social. (RODRIGUES, 2015, p. 57).

A biografia, por sua vez, pode ser considerada, através de documentos orais, escritos ou imagéticos, indutora de pertinentes análises historiográficas dos acontecimentos individuais das várias fases da vida de uma pessoa ou personagem, no imbricamento com o coletivo, ganhando relevo na preservação da memória social. (BORGES, 2008).

Ainda que os estudos biográficos no Ocidente tenham sido, por longos tempos, marcados por uma idade heroica, modal, esta se desprende das hagiografias e dos "heróis nacionais" para as idades hermenêuticas que concebem todos os indivíduos como sujeitos de história. Longe da visão linear e teleológica proposta pelos primeiros estudos biográficos, esta biografia, assim como as novas análises, preocupa-se em evidenciar a "[...] dialética entre acontecimentos, conjunturas e estruturas, elites e massas, indivíduos e grupos, palavra e ação". (LORIGA, 2011, p. 139).

Vale destacar que a aproximação entre a História e a biografia, após o Movimento dos Annales, ocorreu com maior impulso a partir dos anos de 1960. Nessa perspectiva, em meados de 1970, Bourdieu (1996) critica a biografia como trajetória estabelecida e propõe a abordagem de uma biografia que analise a ação e representatividade do indivíduo na constituição, organização e manutenção nos diferentes campos de atuação social, tais como o político, o religioso, o econômico, o intelectual e o libertário. Já Levi (1996) entende a biografia como um espaço, um lugar de tomada de decisões no qual transpiram tensões entre a racionalidade dos sistemas sociais e de emancipação dos indivíduos. Em vez da história política com o olhar das poltronas imperiais ou presidenciais que valora a "históriatotal ou global", no sentido de "[...] uma correlação entre todas as instâncias de uma sociedade, que expressariam um fato total" (REIS, 2000, p. 80), verdadeiro e inquestionável, a biografia de Henriqueta procura nas partes a presença do todo, ao permitir articular o individual ao social, o micro ao macro. (LORIGA, 2011).

Importa enfatizar que o método biográfico utilizado no campo da História da Educação endossa a compreensão de que o indivíduo e a sociedade são esferas inseparáveis da narrativa histórica, ao entender a realidade como um "[...] conjunto mutável de interdependência entre os indivíduos na totalidade das suas ações e múltiplas experiências de vida, em suas intricadas relações sociais". (MACHADO, 2010, p. 115). Salienta-se, pois, que, na interface Educação e História, a biografia de educadoras permite analisar hermeneuticamente a diversidade de professoras em suas particularidades, considerando a história das práticas e as representações educativas que fomentam a trajetória docente, de maneira contextualizada, inclusive possibilitando alargar a compreensão de aspectos culturais e sociais que perpassam o imbricamento entre a vida individual e coletiva.

$O$ alcance das fontes que embasaram o artigo não foi simples. A pesquisa espontânea no Google direcionava, primordialmente, para endereços situados à Rua Henriqueta Galeno e à Escola Henriqueta Galeno, ambas nomeadas em homenagem à literata objeto deste estudo, não aparecendo, no entanto, nenhum texto científico. A busca 
pela produção acadêmica sobre "Henriqueta Galeno" iniciou-se no banco de teses e dissertações da Coordenadoria de Aperfeiçoamento de Pessoal de Nível Superior (Capes), não se encontrando nada com esse descritor. Fato idêntico ocorreu na busca realizada no Scientific Electronic Library Online (Scielo). Já no portal de periódicos da Capes, no campo "buscar assunto", localizaram-se cinco registros, destes, quatro se referiam a endereços situados à Rua Henriqueta Galeno e apenas um fazia menção à educadora. Esse documento tratava de uma homenagem a Heloneida Studart, escrita por Cunha (2008, p. 272), que menciona uma única vez o nome de Henriqueta ao inferir que Heloneida "[...] foi participante da Casa de Juvenal Galeno, da chamada Ala Feminina, organizada por Henriqueta Galeno". Segundo a referida autora, Heloneida, por ser feminista e trabalhar fora, teria sido um desgosto para a mãe.

A homenagem a Henriqueta Galeno com nome de escola e rua gerou uma dualidade instigante: ao tempo que a sociedade "imortaliza" a educadora, condecorando-a em placa e denominação de prédio público, não há qualquer estudo que possibilite preservar sua história e memória, ainda que seu nome seja amplamente conhecido no estado do Ceará, em especial pelos intelectuais. Ante a ausência de pesquisas e representatividade social de Henriqueta Galeno, constatou-se a importância de prosseguir com a pesquisa.

A procura por documentação que pudesse viabilizar a biografia de Henriqueta foi desenvolvida em diversos locais: 1) na Biblioteca da Casa Juvenal Galeno, na qual se identificaram as primeiras fontes da biografada: livros Mulheres do Brasil (1971), Henriqueta no Congresso Feminino, na academia Carioca de Letras e no Centro Cearense (1932) e Mulheres admiráveis (1967); 2) no Arquivo do Instituto do Ceará, localizando publicação da revista do próprio instituto; 3) na Hemeroteca da Fundação da Biblioteca Nacional, no Rio de Janeiro, encontrou-se a Revista O Cruzeiro, que narrava a participação de Henriqueta no Congresso Internacional Feminino; 4) na Hemeroteca da Biblioteca Pública Menezes Pimentel, onde se localizaram relatórios do governo do estado, Mensagem da Assembleia, Diários Oficiais; 5) na Hemeroteca do Centro Nacional de Folclore e Cultura, onde se localizou o jornal que noticiou sua morte; 6 ) no cemitério em que foi enterrada, São João Batista, no qual não havia um sepulcro individual, apenas uma lápide - "Família Juvenal Galeno" -, sem nenhum outro registro; e 7) nos colégios em que estudou, Imaculada Conceição e Liceu do Ceará, nos quais nenhuma documentação foi encontrada. Importa esclarecer que as "[...] fontes não supriram por completo a biografia [...], nem esvaziaram as possibilidades de emergência de novos dados" (ALMEIDA, 2017, p. 339), mas foram todos os documentos encontrados, depois de exaustiva busca, para amparar a narrativa biográfica.

\section{O tempo de Henriqueta Galeno}

No contexto sócio-histórico da mulher cearense oitocentista, apesar das diversas transformações, sua inserção educacional ainda era irrisória; o analfabetismo vigorava na sociedade brasileira desse século. De acordo com Girão (1979), os principais locais de ensino das meninas e moças de Fortaleza era o Colégio da Imaculada Conceição (de meados de 1860), junto com o Seminário Episcopal (1864).

No início do século XIX, em meio às 43 escolas masculinas do estado do Ceará, apenas nove eram destinadas ao gênero feminino. Pouco mais da metade dos habitantes 
de Fortaleza não sabia ler e escrever no final desse século. Esse cenário era resultado de uma sociedade patriarcalista e machista, em que havia o temor dos pais de que suas filhas pudessem desviar o caminho da escola em direção aos flertes e às correspondências amorosas, perdendo sua "honra", bem como a crença de que a mulher não necessitava de elevada escolarização; era preciso ser "maternal, culta e recatada". (LIMA, 2017).

A prática do estudo feminino ficava a cargo da estirpe mais abastada, isto é, dos "bem-nascidos", e, ainda assim, em espaços reservados e sob olhares atentos que disciplinavam os corpos. (FOUCAULT, 1986). Esta biografia de Henriqueta Galeno (18871964), ao problematizar sua educação e participação no movimento feminista, fomenta a compreensão dos mecanismos de fuga das moças "de família" e põe em discussão paradigmas, valores, costumes e tradições que serviram de sustentáculo para as sujeições do feminino na primeira metade do século XX.

Ainda que na segunda metade do século XIX a concepção do que seria "mulher" tenha sofrido transformações mais enfáticas, já que a companhia da figura masculina nos passeios, nas lojas e nos espaços públicos foi sendo minimizada, isto é, no meio social a mulher foi ganhando novas características e atribuições que não mais necessitavam do ladeado masculino. O novo lócus do gênero feminino fixava-se especialmente nos balcões, nas fábricas, nas grandes casas, nas agremiações literárias, nas editoras, nos jornais e nos ambientes escolares. (MALUF; MOTT, 1998).

Desse modo, biografar Henriqueta perpassa pelo surgimento dessa "nova mulher", "[...] sempre encarnada em pessoas e contextos reais" (THOMPSON, 2004, p. 10), que elaboraram dinamicamente suas próprias formas culturais, de convivência social e resistência - experiências - em determinado período histórico; e não como algo imóvel, uma categoria ou estrutura estática.

Nesse contexto feminino do primeiro quartel do século XX, diversos preceitos do Código Civil de 1916 sacramentavam a inferioridade da mulher casada ao marido. Ao homem, chefe da sociedade matrimonial, competia a representação legal da família, a organização de seus bens materiais e singulares da esposa, o direito de escolher em qual local residir. Assim, a referida ordem jurídica legitimava o molde que estabelecia a mulher como subordinada ao marido, restando a ela o dever de cuidar do lar - casa, filhos e marido -, sem igualdade de direito civil. (MALUF; MOTT, 1998).

Vale destacar que a própria cultura deve ser vista como um espaço de conflito mutável (THOMPSON, 1998), ou seja, as mulheres não foram meras vítimas passivas na história, mas sim sujeitos ativos e capazes de promover mudanças no contexto pessoal e no próprio contexto político, econômico, social e cultural. É com essa compreensão que se enseja luz à vida de Henriqueta Galeno, mulher que atuou ativamente nas transformações socioculturais de seu tempo.

Nas terras alencarinas, importa destacar as figuras de mulheres imortalizadas em estudos científicos, por exemplo: Francisca Clotilde, primeira educadora da Escola Normal (ALMEIDA, 2012), e Alba Valdéz, primeira mulher a ingressar na Academia Cearense de Letras e a se engajar na Liga Feminina (SÁ; FIALHO, 2016), o que contribui para a preservação das histórias e memórias das mulheres no Brasil, em especial, do Ceará. Henriqueta Galeno, primeira professora do Liceu do Ceará, mesmo se constituindo figura atuante na sociedade fortalezense, ainda não desfrutava da mesma visibilidade, o que tornou relevante empreender esta pesquisa biográfica. Com esse mote, biografa-se aqui 
Henriqueta Galeno, enfatizando hermeneuticamente sua atuação como sujeito de uma história dinâmica, com olhar holístico que busca compreender comportamentos e ações, considerando o tempo histórico e a conjuntura político-social em tela.

\section{A educação, a profissionalização e a participação no movimento feminista}

Diferentemente da maioria das fortalezenses de seu tempo, a educadora Henriqueta Galeno seguiu uma trajetória singular, na contramão da esperada para as boas moças: alcançar um matrimônio, constituir família e se dedicar ao lar. Optou, ante as possibilidades que the foram proporcionadas, a se dedicar ao universo letrado, valorizando a leitura e a produção de textos que punham em xeque os valores disseminados, descortinando paradigmas e questionando a cultura patriarcalista local. Mesmo não galgando a devida visibilidade, por estar duplamente obscurecida: ser figura feminina e ter um pai muito influente a quem se destina a maior parte das atenções da sociedade, Juvenal Galeno², Henriqueta fez-se importante para História da Educação por disseminar ideias feministas e por demonstrar às outras donzelas da alta sociedade, mediante sua história, que era possível traçar objetivos de vida para além da esfera doméstica e conseguir respeito pelos "temidos" conhecimentos sociopolíticos e pela independência financeira da mulher.

Henriqueta Galeno nasceu numa Quarta-Feira de Cinzas, em 23 de fevereiro de 1887, na residência de número 272, atualmente denominada Rua General Sampaio, na cidade de Fortaleza, estado do Ceará. Após 40 dias do seu nascimento, foi batizada na capela do Sagrado Coração de Jesus, acompanhada de seus padrinhos - o Padre Antônio Xisto Albano (que também ministrou o referido sacramento) e a irmã de seu pai, Florentina da Costa Justa. (BÓIA, 1986).

Seus genitores foram Juvenal Galeno (1836-1931) e Maria (Mariquinhas) do Carmo Cabral Galeno (1856-1942). Seus irmãos José Maria, Antônio, Maria do Carmo e José nasceram em Aratanha, no Sítio da Boa Vista; Júlia e João, assim como Henriqueta, nasceram na residência dos pais em Fortaleza, onde hoje é situada a Casa de Juvenal Galeno. (SÁ, 1971).

A família de Henriqueta Galeno pode ser considerada abastada, pois seguia os moldes da elite fortalezense dos fins do século XIX e início do XX. Seu provedor, Juvenal Galeno, oriundo de estirpe cafeicultora da Serra de Aratanha, teve formação no Liceu do Ceará e concluiu seus estudos em Agronomia no Rio de Janeiro. Ao retornar para a capital cearense, foi deputado estadual em 1859. (ANDRADE, 1948). Posteriormente, exerceu o cargo de inspetor da instrução pública no estado e de bibliotecário público, entre os anos de 1889 e 1908. Sustentou seus rebentos em escolas particulares, tais como a Escola Imaculada Conceição e Liceu do Ceará. Sua casa, pomposa, com vários compartimentos e com excelente mobiliária para o período, foi lócus de apresentação de saraus literários e eventos políticos, possuindo até auditório. (SÁ, 1971). Assim, por seguir a prole de grande prestígio social, pode-se considerar que Henriqueta Galeno teve uma "privilegiada" formação intelectual que subsidiou sua atuação como educadora, literata e feminista.

\footnotetext{
2 Juvenal Galeno foi considerado o primeiro literato da cultura popular nordestina, autor de poéticas cheias de lirismo, como Prelúdios poéticos, A machada, O matuto e Porangaba. Contemporâneo de Machado de Assis, escreveu para diversas instituições acadêmicas e jornais cearenses e cariocas. (Revista O Cruzeiro, 1957). Nasceu em Pacatuba (CE), no ano de 1836, no Sítio da Boa Vista, e faleceu em 1931.
} 
Henriqueta, como era comum no período, foi instruída quanto às primeiras letras em sua residência, por meio de educadores particulares. Nini Dodt Barroso, irmã do beletrista Gustavo Barroso, foi sua principal professora. Ainda que aluna exemplar, em relação ao ensino das prendas domésticas, a biografada nunca foi bem-sucedida: "[...] na 'sala da bola', com as venezianas que davam para a rua fechadas, entregavam-se à tarefa de bordar e costurar [...], que era uma negação para essas habilidades manuais, sofreu, com a sua tendência declarada por livros, a oposição da época". (SÁ, 1971, p. 573).

Importa esclarecer que Henriqueta e suas irmãs, Maria do Carmo e Júlia Galeno, tinham aulas particulares pela manhã; logo depois do almoço, as meninas chegavam na "sala da bola", com as venezianas fechadas para a rua, pegavam as agulhas e linhas para aprender o ofício de bordar flores e ramos de toalhas, colchas e pastas, também havendo tempo para as receitas culinárias e demais aprendizagens que não poderiam faltar à boa esposa, no entanto Henriqueta não teve o mesmo bom desempenho na arte do bordar que suas irmãs. (SÁ, 1971).

Enquanto todas as irmãs de Henriqueta Galeno conseguiram um matrimônio interessante para as moças e suas famílias, Henriqueta sequer namorou. Seu objetivo de vida vislumbrava os estudos, a formação em nível superior e a independência financeira. Esse escopo destoava ao das outras moças de sua idade e classe social, que se preocupavam com um bom casamento e com a constituição de uma família. Como contraposição, salienta-se que a figura da mulher "solteirona" era motivo de estranhamento e chacota. (SOIHET, 2000).

Consoante Oliveira (2007), a vontade do pai de Henriqueta, o poeta Juvenal Galeno, de que sua filha se dedicasse a difundir a cultura e os movimentos ligados ao regionalismo cearense, já que tanto amava os livros e a cultura letrada, era explícito. Naturalmente, seu pai não imaginava que tal percurso fosse pilar basilar para o futuro envolvimento com a militância feminista. Provida de rico arcabouço intelectual e apoiada por Juvenal Galeno, homem de renome e prestígio social, Henriqueta realizou seu objetivo de ser uma bacharel. Esse percurso, incomum para as mulheres da época, foi permeado por enfrentamentos, retaliações, sucessos e percalços, que transitavam entre a sujeição paterna e o empoderamento feminino.

O Liceu, mais conceituado colégio de ensino secundário do Ceará da época, foi fundado em 1837. (VITOR, 1945). Apenas 70 anos depois, formou-se nessa instituição como bacharel em Letras Henriqueta Galeno. As Escolas Normais eram os locais de conclusão do ensino secundário das moças nesse período, que contemplava a formação das professoras para o ensino primário. O relatório de Nogueira Accioly explicita o motivo pelo qual as Escolas Normais possuíam, em maioria, o sexo feminino no corpo discente:

Se bem que os regulamentos da Escola Normal não tenham excluido o sexo masculino de suas classes, é facto notório, digno de reparo, a ausencia completa de moços ás disciplinas de seu curso. No Ceará o privilegio feminil tornou-se quasi exclusivo, parecendo significar que as aptidões do sexo masculino the são inferiores neste particular. No entanto, se a mulher por suas faculdades affectivas é mais meiga para as creanças, se economicamente grava menos os cofres do Estado por se contentar com estipendio menor, faltam-Ihes outros predicados pedagogicos de capital importancia no ensino: têm menos espírito de continuidade, menos energia para se impôr a alumnos recalcitrantes, sobretudo aos de mais de 12 annos, menos resistenciaá fadiga physica e mental, inferioridade de noções praticas, mais mobilidade de opiniões e de sentimentos, maior impressionabilidade nervosa, etc., 
o que não constitue precisamente as qualidades primordiaes, selectas, viris, capazes de suggestionar sentimentos alevantados no animo infantil, preparando-o para as agruras da existencia rude e afanosa do nosso meio. (Relatório de Accioly, 1899).

Desse modo, os homens não se faziam necessários nas Escolas Normais, uma vez que cabia às mulheres frequentar seus bancos, haja vista que as mesmas eram mais dóceis e pacientes com os pequenos, bem como por constituírem uma mão de obra mais barata ao Estado, já que as mulheres não precisavam ganhar bem, pois eram os homens quem deveriam prover financeiramente o lar. (OLIVEIRA, 2002). Para o período, considerandose que o papel do sustento dos lares cabia ao sexo masculino, as moças de família poderiam atuar no ensino primário até conseguirem matrimônio, dado que tal atividade era considerada uma extensão do lar e uma espécie de exercício dos dotes maternos (OLIVEIRA, 2002); inclusive, não apenas os homens, mas as próprias mulheres das classes mais altas incorporavam "[...] sua responsabilidade moral e a necessidade de instruir um moderado bem viver". (ANDERSON-FAITHFUL, 2012, p. 25). Em consonância ao Relatório de Accioly (1899), o Liceu do Ceará era lugar para homens, pois às mulheres "[...] têm menos espírito de continuidade, menos energia para se impôr a alumnos recalcitrantes, sobretudo aos de mais de 12 annos".

A averiguação do intelecto humano estava calcada em questões de gênero. Os relatores do referido relatório político justificavam a ciência determinista da época, bem como o argumento de que o homem possuía habilidades de educar melhor os conteúdos propedêuticos e instaurar a ordem, visto que a probidade da educadora, sua cautela e seu espírito maternal não eram suficientes para lhe habilitar a ministrar conteúdos além de letras e algarismos. Tomaz Pompeu (1919) asseverava em relatório governamental que, após a puberdade, pelo surgimento de sensibilidades viris, o alunado do ensino secundário necessitava de palavras e ensinamentos mais rudes para atuar na vida pública. Para tanto, fazia-se necessária a figura do professor masculino, uma vez que "[...] não falece a mulher o sentimento cívico, o amor da pátria, não tem por experiência pessoal, como o homem, o conhecimento e a prática dos deveres cidadãos". (CEARÁ, 1919).

No Liceu do Ceará, todavia, a situação se apresentava contrária à Escola Normal, dado que eram os homens a maioria dos frequentadores, tanto na condição de alunos como na de professores. Henriqueta, contudo, foi exceção duas vezes: primeiro na condição de primeira discente menina; segundo na obtenção de ótimos rendimentos e no reconhecimento de seus colegas e professores.

Após a conclusão do Curso Normal, Henriqueta optou por cursar bacharelado em Direito; seu ingresso foi fluido devido à bagagem acumulada ao longo dos ensinos primário e secundário. Segundo o Diário Oficial do Estado do Ceará, Henriqueta Galeno ingressou na Faculdade de Direito do Ceará na quarta-feira de 2 de dezembro de 1914. Aos dias 24, 25, 26 e 27 do referido ano, realizou os exames junto a seus colegas homens e a outra moça, de nome Odette Correia de Menezes, obtendo aprovação em Enciclopédia Jurídica com média oito e em Direito Constitucional com média oito e meio, sendo, mais uma vez, pioneira no campo educacional masculino, por ser a primeira aluna da Faculdade de Direito do Ceará. Após quatro árduos anos de estudos exclusivos, Henriqueta Galeno, no final de 1918, terminou as disciplinas, colando grau em 9 de abril de 1919, destacando-se por sua trajetória acadêmica exemplar. Começou-se, assim, uma nova fase de sua trajetória, aos 
32 anos de idade, agora bacharela em Ciências Jurídicas e Sociais.

Na sua festa de formatura, evento social de grande prestígio, por ser os cursos de Direito e de Medicina os mais requisitados pela elite cearense, em meio às várias personalidades, Henriqueta Galeno realizou proclamações poéticas e performances de danças na referida noite estrelada. Nessa circunstância, o presidente do estado - Dr. João Tomé - indagou, em fala informal, se a nova bacharela gostaria de se promover ao exercício de promotora pública. O convite despertou-Ihe imediato interesse, no entanto o aceite não foi efetivado por intervenção do seu pai, que não a autorizou e a fez declinar do cargo.

O fato narrado se ampara no relato de Henriqueta em Mulheres admiráveis (1965), ao inferir que, logo quando realizou o curso de Direito na Faculdade do Ceará, o presidente do estado a nomeou promotora da capital, deixando-a confiante e esperançosa, chegando a sair a notícia no Jornal da Manhã, dirigido pelo jornalista Luis Santos, presente na reunião em que havia sido nomeada. Entretanto, o pai de Henriqueta não lhe permitiu que ocupasse tal cargo, temendo que ela "perdesse a honra" (SÁ, 1971), já que esses espaços eram ocupados exclusivamente por homens.

Henriqueta Galeno se subjugou à autoridade do pai e foi compor o quadro efetivo do magistério do Liceu do Ceará, sendo inspetora do secundário e lecionando a cadeira de História do Brasil por dez anos. Como professora, ainda que no ensino secundário, seu pai sentia-se mais confortável, posto que o magistério era lugar consagrado de mulheres.

O relatório do governador do Ceará de 1918 relatava como se dava o processo de escolha do corpo docente do Liceu do Ceará: através do gênero, da formação acadêmica de bacharel, do resultado satisfatório nas provas da seleção e da boa índole e decoro social.

[...] professorado masculino, escolhido entre indivíduos cuja capacidade seja assegurada pelo certificado dos estudos que tenham realizado, e pelo resultado satisfatório das provas a que se submeterem é capaz de, senão realizar o milagre da perfeita difusão do ensino, ao menos minorar os defeitos que acentualmente o inquinam. (CEARÁ, 1918).

Henriqueta obteve os documentos solicitados oficialmente para o cargo: 0 certificado assegurando capacidade e bons resultados nas provas; também possuía os requisitos extra oficiais: índole e prestígio social. Oliveira (2007) afirma que Henriqueta Galeno foi a primeira e única mulher docente do Liceu entre os anos de 1922 e 1929. No entanto, por ser mulher, sofreu preconceitos e enfrentou os comentários pejorativos acerca de sua presença no Liceu; sempre muito firme nas suas decisões e responsável como profissional, conquistou admiradores, mas também gerou inimigos. (ADERALDO, 1977). Esses emergiam especialmente por não aceitarem uma mulher ocupando profissão de prestígio, que era ser docente do Liceu, até então concebido como espaço exclusivamente masculino. Aderaldo (1977) assevera o exposto:

A História do Brasil era ministrada na $5^{a}$ série (1933) por Henriqueta Galeno, filha do velho bardo das 'Lindas Canções Populares', mulher de muitos méritos e muitos inimigos, que lhe moviam persistente e injusta campanha, só aferecida no tempo. O Ceará Ihe deve serviço inestimável na promoção de seus maiores filhos no campo intelectual. Estimei-a muito, anos depois, e creio que fui por ela estimado também.

É oportuno avultar nesta investigação o quão intenso era o preconceito, o qual, em março de 1932, fez com que a personagem aqui biografada forçadamente se afastasse de 
suas atividades laborais no Liceu do Ceará, "[...] deixando seu nome de constar das folhas de pagamento da Secretaria de Educação, manobra que visava o aproveitamento, para o seu lugar, do professor Antônio Teófilo". (BÓIA, 1996, p. 48). Depois de movimentos políticos de seu pai, de alunos admiradores e da própria Henriqueta, por decisão do interventor Capitão Carneiro de Mendonça, foi-lhe restabelecida sua funcionalidade educacional em junho daquele mesmo ano. Tal intempérie afastou Henriqueta com base unicamente na sua condição feminina, mas, em vez de deixá-la abatida, serviu-lhe de motivação para que, por mais de três décadas, trabalhasse como docente e, inclusive, galgasse 0 cargo de Inspetora Federal do Ensino Secundário ${ }^{3}$, escoltando e supervisionando vários colégios secundários da capital cearense.

Desde sua tenra idade, Henriqueta recebeu influências de seu pai, o educador e escritor Juvenal Galeno, para sua bagagem intelectual, mas, somente após a morte do pai, Henriqueta ganhou mais visibilidade e independência no mundo letrado. Em sua miniautobiografia - publicada como capítulo na obra Mulheres admiráveis -, ela relata que nasceu e se criou na cidade de Fortaleza, na mesma residência onde habitou toda a sua vida, na qual viveu por mais de cinco décadas, tendo sempre como exemplo de vida seu genitor, Juvenal Galeno, fundador da poesia popular brasileira.

Juvenal Galeno, renomado líder literato oriundo das elites cearenses, foi figura de inspiração pessoal para Henriqueta, num duplo movimento contraditório: ao tempo que impelia na filha o incentivo aos estudos e ao ingresso no mundo letrado, delimitava os espaços de atuação profissional e até onde poderia chegar a "mulher de família". Ainda que seu genitor a estimulasse nos estudos, tolhia-lhe ao não permitir seguir seus passos, relegando-a à sua sombra, como confirma sua narrativa, na qual explica que sempre respeitou e obedeceu ao pai, realizando, apenas depois da morte dele, alguns objetos almejados e sancionados: "Só depois da morte de meu pai é que fiz a minha primeira viagem ao Sul do país”. (GALENO, 1965, p. 3).

A admiração da filha pelo pai serviu de impulso para que ela fundasse a Casa Juvenal Galeno, uma espécie de biblioteca e também de museu de seu pai, lugar de preservação da memória do intelectual e de abrigo e estímulo aos que apreciam atividades intelectuais e culturais. Henriqueta Galeno cuidou do pai até a morte dele, doando inclusive seu próprio punho para a escrita do patriarca ao ser acometido por cegueira. "Sua dileta filha e secretária dedicada, carinhosamente conserva como um douto instituto da casa que durante longos anos viveu em Fortaleza [...]”. (Revista O Cruzeiro, 1957, p. 21).

Pode-se inferir, analisando a vida da biografada, que o padrão econômico da sua família, bem como a inserção social e o estímulo originário do seu pai, foram fatores preponderantes para que Henriqueta se tornasse uma educadora e literata de certa visibilidade. Tais fatores, no entanto, não foram determinantes, prova disso são as trajetórias de suas irmãs, que não seguiram o mesmo caminho. Defende-se, em consonância, que Juvenal, à medida que serviu de inspiração e estímulo à trajetória profissional de Henriqueta, também a obscureceu.

\footnotetext{
3 O cargo de inspetora federal do ensino secundário foi decorrente da nomeação realizada pelo Dr. João Tomé, governador do Estado do Ceará de 1916 a 1919 e senador entre 1921 e 1930. Segundo Bóia (1986, p. 48), Henriqueta Galeno "Durante trinta e um anos, como Inspetora Federal do Ensino Secundário, acompanha e fiscaliza a vida escolar de vários colégios dessa capital". A ausência de fontes, todavia, não permitiu maiores informações e discussões sobre sua atividade profissional nesse cargo.
} 
A escolha pelo mundo letrado não foi tão fácil, Henriqueta teve que vivenciar momentos de solidão e enfrentar o preconceito de não possuir um companheiro. Vale mencionar, inclusive, que as mulheres muito cultas e independentes espantavam os homens, ou seja, os pretendentes, haja vista não ser esse o padrão de boa esposa procurado pelos jovens naquela sociedade machista. (SÁ, 1971).

O feminismo cearense, que muito encantava Henriqueta, apesar de ela preservar silêncio sobre tal ideologia por respeito ao pai, teve início por volta de 1904, quando Alba Valdéz inaugurou e presidiu a Liga Feminista Cearense, pioneira agremiação literária feminina no Ceará.

Em dois artigos publicados no Correio do Ceará de 22 e 23 de junho de 1917, sob o título A Mulher perante o Direito Social, já se preocupava com o feminismo. A mesma Alba Valdéz, ainda pelo mesmo diário, cinco dias depois, estampava uma carta, O Voto Feminino, endereçada a Adelaide Amaral. E esta, em primeiro de agosto, ainda em 1917, realizava, nos salões da Fênix Caxeiral, com as presenças do presidente João Tomé e de Leonardo Mota, às vinte horas, sua conferência subordinada ao tema Problema do Feminismo e suas Modalidades. (BÓIA, 1986, p. 50).

Somente cerca de 30 anos passados das primeiras iniciativas feministas no estado, Henriqueta Galeno começou a se pronunciar mais enfaticamente, após a morte de seu pai, em março de 1931. Ela defendia a tese de que a mulher deveria ter oportunidades de acesso às profissões na mesma proporção que os homens, inclusive com igualdade salarial. Rapidamente tornou-se assídua e respeitada nos movimentos feministas.

Henriqueta Galeno, ainda em 1931, apartou-se da Terra do Sol a caminho do Rio de Janeiro, acompanhada da beletrista Adília Albuquerque, como representante dos anseios das mulheres cearenses no $2^{\circ}$ Congresso Internacional Feminista, liderado pela cientista e também feminista Berta Lutz, que era "[...] conhecida como pioneira na luta pelos direitos das mulheres, pela paixão aos museus como espaço de educação e por sua produção científica". (SILVA JÚNIOR; RODRIGUES, 2015, p. 112). No referido congresso, a personagem aqui biografada asseverou:

Passo a expor-vos as minhas idéas feministas. Entendo que o feminismo deve, quanto antes, entrar altiva e corajosamente na liça. [...] Quebremos, num gesto resoluto, estes grilhões que, por dezenas de anos, nos têm acorrentado e rebaixado a uma situação de seres inferiores, incapazes de ter uma celebração semelhante á do homem e poderem participar, igualmente, dos direitos sócio-políticos conferidos áqueles. Não pretendemos pedir nenhum favor e nema concessão de um privilegio, que nos obrigue a uma gratidão nunca assás demonstrada ao dadivoso reformador. Pedimos é a justiça igualitária, que nos conceda, enfim, o nosso direito, até então sonegado. Pretendemos participar igualmente das mesmas vantagens e das mesmas desvantagens dos sêres masculinos, em todas as atividades humanas. Não queremos mais ser afastadas do desempenho de um cargo publico, ou que se nos vede o seu acesso com o eterno e fragílimo pretexto de não o podermos ocupar, pelo simples fato de se pertencer ao sexo feminino. Ora, não há nada de mais absurdo, de mais atentatório aos direitos alheios. Para que serve a Constituição do meu país? Acabemos de vez com este absurdo. A mulher deve exercer toda e qualquer função publica, devendo-se-Ihe exigir somente que ela tenha o necessário preparo para o cargo que pleiteia. Não se cogite de sexo, e sim de sua capacidade no desempenho das funções por ela exercidas. (GALENO, 1932, p. 8).

Nessa perspectiva, uma das principais preocupações na defesa feminista de Henriqueta consistia na obtenção da emancipação econômica da mulher, por meio de seu 
próprio esforço, que para tanto se fazia necessário o livre exercício de todas as atividades sociais. Diferentemente de Berta Lutz, o direito ao voto estaria em segundo plano, pois a questão de subsistência e de independência financeira da mulher era uma das causas mais urgentes no feminismo. Ainda em sua tese defendida no Congresso Internacional Feminista, salientou:

A sujeição econômica da mulher é, a meu ver, uma degradação para a própria mulher. E o que póde valer o sêr degradado? O voto, no meu modo de encarar o problema, não deve ser a principal questão. Claro está que devemos exercer os direitos políticos, como as mulheres do velho mundo e da America do Norte. Agora é oportuno pleitearmos o exercício desse direito em face da profunda transformação politica por que passou o nosso país. Dizem os nossos opositores que um parlamento com mulheres seria um pandemônio. No entanto, como é do conhecimento geral, do Congresso do nosso país, ainda não fez parte a mulher, e até agora não têm faltado ao recinto imponente do nosso Parlamento as gritarias, os barulhos, a confusão, a balburdia e, por que não dizel-o?, até cenas de pugilato. E as grossas somas no Tesouro Nacional a compensar estes 'afanosos e ordeiros' trabalhos! [...] Deve ser essa a nossa maior e mais urgente conquista, o ponto convergente da concentração de nossas supremas energias! Eis, portanto, a nossa bandeira, a emancipação econômica da mulher e, consequentemente, o seu livre acesso a todos os cargos administrativos, tendo-se em mira unicamente as suas qualidades, intelectuais e morais, talqualmente se deve fazer para com o sexo masculino. O meu feminismo converge especialmente para este ponto. Resolvamos sem temores e nem falsos e antiquados preconceitos a nossa situação moral - 0 resto virá naturalmente, depois. Congregadas, coesas e resolutas, saiamos das teorias e, impavidas, firmes, entremos no terreno pratico das lutas e das competições [...]. (GALENO, 1932, p. 10).

Após o Congresso, Henriqueta foi entrevistada pela Gazeta de Notícias (1931), ainda no Rio de Janeiro. O referido jornal noticiou o seguinte: "É um dos nomes de destaque da intelectualidade feminina de sua terra, o que the valeu ser escolhida para representar as aspirações da mulher cearense no recente Congresso Internacional Feminista, onde se houve com assinalado brilho [...]".

Galeno envolveu-se profundamente com a causa feminista, ingressando na cena pública como deputada e apoiando diversos eventos com mote no papel social da mulher. Foi escolhida pelo interventor federal Fernandes Távora, por meio da solicitação de Carmem Portinho, como líder da Federação do Progresso Feminino. O que Ihe interessava no calor do momento era a luta pela concretização dos anseios da liberdade econômica das mulheres. Inclusive rechaçava o casamento para a aquisição de sustento, conforme se pode constatar adiante:

\footnotetext{
E não se venha dizer o contrario. Estar uma mulher sujeita a um homem pelo simples fato de precisar do sustento dele para manter a sua posição perante a sociedade local, muitas vezes possuindo esta mulher mais capacidade do que o seu senhor, isto é, ao meu vêr, verdadeiramente infamante para ela. Não póde haver independência sem emancipação [econômica]. [...] Avancemos, pois, na conquista da nossa liberdade econômica. Lutemos, sem recuos, pela consecução deste intento, sem a nada temer [...]. (GALENO, 1932, p. 10).
}

Afirmava também que não pretendia desafiar os homens para uma luta, nem mostrar a superioridade neste ou naquele ponto, pretendia-se a igualdade. Henriqueta acreditava que as mulheres não deveriam se acomodar à situação de servas, como seres inferiores, conforme ocorria na sociedade brasileira da primeira metade do século XX. Ao 
contrário disso, deveriam buscar a união fraternal, a paz, a harmonia, o amor, sem perderem de vista que as aptidões e os infortúnios da espécie humana não eram divididos por sexos. Explicitou a necessidade da mulher de, por meio de sua coragem, buscar o sustento para sua vida mediante o trabalho, partilhando e participando de todas as atividades sociopolíticas de forma igualitária aos homens. O que almejava era:

[...] que se não sonegue mais os nossos direitos, há tanto postergados. Desejamos compartilhar, igualitariamente, com os nossos pais, com os nossos irmãos, com os nossos amigos do sexo oposto, das mesmas lides afanosas. Aspiramos a ser dos nossos maridos, não somente a companheira física (a quem ele não trata dos seus negócios porque, na sua opinião ela não os compreende...) mas também, e principalmente, a companheira dos afans intelectuais, de trabalhos comuns, de continuas trocas de idéas, sem distinção de assunto, companheira de todas as horas, confidentes de todas as alegrias e pesares, partilhando com eles, honesta e inteligente, uma vida de sêres iguais. (GALENO, 1932, p. 10).

Henriqueta, apesar do envolvimento com a militância feminina e dos cuidados na preservação do Salão Juvenal Galeno, conseguiu se organizar para atuar na Associação de Imprensa e no Instituto Histórico do Ceará; essas atividades profissionais permitiram-Ihe ampliar a divulgação de suas ideias. Também foi congratulada por sua trajetória intelectual, com assento na Academia de Letras do Ceará. (AZEVEDO, 1977).

Após meses de sofrimento por conta de uma moléstia não identificada, faleceu na capital cearense às $12 \mathrm{~h} 15$ da tarde do dia 10 de setembro de 1964 . O velório foi em sua residência, a Casa Juvenal Galeno, sendo laureada por um grande número de pessoas (autoridades, homens de letras, admiradores), conforme registro do Jornal Correio do Ceará de 11 de setembro de 1964. No momento do seu sepultamento, no Cemitério São João Batista, o governador Virgílio Távora determinou "[...] que à ilustre escritora cearense fossem prestadas todas as homenagens do Estado, num preito de reconhecimento ao seu valioso trabalho em favor das letras de nossa terra [...]". (Jornal Correio do Ceará, 11 de setembro de 1964).

\section{Considerações finais}

A pesquisa biográfica explora os processos de origem e de ação dos indivíduos como seres sociais e elenca como eles dão forma a suas experiências, como fazem para significar as situações e as ações que condicionam o seu existir. (ALMEIDA, 2014). Nessa interface do individual e do social no caso aqui em tela - num processo incessante de produção recíproca -, o espaço da pesquisa biográfica consistiu, então, em perceber a relação singular que o indivíduo, Henriqueta, manteve com o mundo histórico, social e cultural pela sua atividade biográfica.

O objetivo da pesquisa foi biografar Henriqueta Galeno com ênfase na sua formação educacional e inserção no movimento feminista. Situada no campo da História da Educação, em especial na história de mulheres, debruçou-se no estudo da vida de Henriqueta Galeno (1887-1964), uma educadora que atuou no cenário patriarcalista da primeira metade do século $\mathrm{XX}$, dedicando-se à intelectualidade e ao feminismo.

Nessa perspectiva, pode-se inferir que a biografia em tela pode servir de fonte para a História da Educação, posto que a biografia acadêmica de Henriqueta Galeno, como arte ou ciência de narrar vidas, seguiu uma pesquisa documental criteriosa que analisou 
diversas fontes - jornais, revistas, autobiografias, etc. - para reconstituir um indivíduo com suas particularidades, ao tempo que extraiu deste certas características típicas que se imbricam no coletivo e permitem discutir o macro pelo micro.

O contexto sócio-histórico do Ceará do final do século XIX e primeiras décadas do século XX caracterizava-se pelo desenvolvimento econômico restrito, com a renda centrada em poucos grupos abastados, numa sociedade acometida por severo desequilíbrio econômico. (PONTE, 2001). O analfabetismo, a fome e a miséria, que assolavam boa parte da população, pareciam não existir para as poucas famílias que possuíam prestígio social, em especial as que habitavam a capital cearense.

No cenário das mulheres da elite, a cultura era marcada pelo patriarcalismo e pelo machismo, que relegavam a mulher, no máximo, à escolarização normal para conhecimentos básicos necessários a uma boa esposa, mãe e dona de casa, podendo a moça atuar como professora das séries iniciais pelo caráter materno "natural" até contrair casamento. Para manter os padrões culturais e sociais, os pais das donzelas zelavam por sua "honra", articulavam casamentos vantajosos economicamente e subjugavam as mulheres à inferioridade intelectual.

A presente pesquisa biográfica da educadora Henriqueta Galeno, ao permitir reflexões acerca da História na interface com a Educação - contextualizando aspectos culturais, sociais e econômicos -, permite afirmar que esse gênero de estudo importa para a História da Educação, uma vez que, ainda que não possa ser generalizável, fomenta a compreensão historiográfica, em especial na área a que se propôs - História da Educação -, visando reconstituir o passado e desvelar narrativas que dão visibilidade a fatos e acontecimentos dos quais se permite emergir uma análise crítica sobre paradigmas e tradições que permearam a história das mulheres no Brasil.

Ao entender a biografia de Henriqueta como um produto de individualidades únicas e irredutíveis, pois "[...] por certo o ser humano está impregnado de história: nasce num seio de uma família, de um povo, de uma linguagem, de um Estado, de uma religião, e assim por diante" (LORIGA, 2011, p. 83), também se torna possível ampliar a compreensão sobre características mais amplas de uma época histórica.

Nascida em família abastada e letrada, Henriqueta teve possibilidades de galgar seus estudos primários com professoras particulares, frequentar as melhores instituições educacionais da sua cidade no período em tela: Imaculada Conceição e Liceu, posteriormente bacharelando-se na Faculdade de Direito da atual Universidade Federal do Ceará. Ainda que amparada pela condição financeira favorável, Henriqueta destoou das mulheres de seu tempo, optando por cursar o secundário propedêutico em vez do magistério, não contrair casamento e formar-se em Ciências Jurídicas e Sociais, tornandose bacharel em Direito.

Ainda que o ambiente doméstico tenha sido essencial na educação formal e informal de Henriqueta, pois seu pai era um prestigiado intelectual e romancista contemporâneo que a influenciou na propulsão acadêmica, também lhe foi repressor, ao tolher-lhe oportunidades de emprego e participação social em movimentos feministas. Atuação esta só desenvolvida após a morte do seu pai. Henriqueta Galeno levou boa parte da vida a divulgar outros escritores, em especial o próprio pai, para o qual fundou o Salão Juvenal Galeno (1919) in memoriam.

Uma das primeiras garotas a estudar no Liceu, pioneira como docente dessa 
instituição e como aluna da Faculdade de Direito no Ceará, Henriqueta rompeu paradigmas e enfrentou preconceitos quanto ao lugar da mulher na sociedade. Foi considerada "[...] a conselheira de toda uma geração de intelectuais, artistas e literatos cearenses [...]" (SÁ, 1971 , p. 575), ganhando prestígio que Ihe conferiu coragem para atuar enfaticamente nos movimentos feministas após o falecimento do pai. A educadora não se limitava à luta pelo direito de voto feminino, propagando também ideais de liberdade profissional da mulher, independência financeira e igualdade de condições entre mulheres e homens, sem sobrepor um sexo ao outro.

Henriqueta, em vez de reproduzir o modelo de sociedade elitista e machista que inferiorizava a mulher, demonstrou para a sociedade cearense, com discursos e ações, que o "sexo frágil" também poderia ocupar lugares até então exclusivos aos homens, em iguais condições intelectuais e salariais. Foi importante na ruptura com paradigmas engessados nos meandros da educação e na difusão de ideias feministas. Contudo, obscurecida pelo prestígio do pai, que se destacou como escritor e poeta, seus feitos, até então, não ganharam a devida visibilidade. Em razão desse fato, este estudo busca preservar a história e a memória de Henriqueta, ao tempo que permite ampliar a compreensão acerca da História da Educação.

\section{Referências}

ACCIOLY, Antônio Pinto Nogueira. Mensagens de Presidente de Província apresentadas à Assembleia Legislativa do Estado do Ceará (1889). Disponível em: <http://www-apps.crl.edu/brazil/provincial/cear\%c3\%a1 >. Acesso em: 10 jul. 2016.

ADERALDO, Mozart Soriano. O Liceu do meu tempo. Fortaleza: Revista do Instituto do Ceará, 1977.

ALMEIDA, Francisco Alves de. A biografia e o ofício do historiador. Dimensões, Rio de Janeiro, v. 32, p. 292-313, 2014.

ALMEIDA, Gildênia Moura de Araújo. Mulheres beletristas e educadoras: Francisca Clotilde na Sociedade Cearense, de 1862 a 1935. 2012. Tese (Doutorado em Educação) Programa de Pós-Graduação Brasileira, Universidade Federal do Ceará, Fortaleza, 2012.

ALMEIDA, Wilson Ricardo Antoniassi de. Professor Leovegildo Chagas Santos (1955): patrono do terceiro grupo escolar de Limeira, estado de São Paulo. História da Educação, Porto Alegre, v. 21, n. 52, p. 335-355, 2017.

ANDERSON-FAITHFUL, Susan. Uma "missão para civilizar": a visão de educação popular do Sindicato de Mães Anglicanas e da Sociedade de Amigas das Moças (1886-1926).

Revista Brasileira de História da Educação, Campinas, v. 12, n. 1 (28), p. 15-44, 2012.

ANDRADE, Francisco Alves de. O pioneiro do folclore no Nordeste do Brasil. Fortaleza: Revista do Instituto do Ceará, 1948.

AZEVEDO, Sânzio de. Literatura cearense. Fortaleza: Academia Cearense de Letras, 1977.

BARROSO, Gustavo. O poeta do cajueiro e da jangada. Revista O Cruzeiro, 30 mar. 1957. Rio de Janeiro: Hemeroteca do Arquivo da Biblioteca Nacional, 1957.

BÓIA, Wilson. Ao redor de Juvenal Galeno. Fortaleza: Imprensa Oficial do Ceará, 1986.

BOURDIEU, Pierre. A ilusão biográfica. In: AMADO, Janaína; FERREIRA, Marieta de Moraes (Org.). Usos \& abusos da história oral. Rio de Janeiro: FGV, 1996. p. 183-191. 
BORGES, Vavy Pacheco. Grandezas e misérias da biografia. In: PINSKY, Carla Bassanezi (Org.). Fontes históricas. 2. ed. São Paulo: Contexto, 2008. p. 203-223.

CEARÁ. Diário Oficial do Estado do Ceará. Fortaleza: Hemeroteca da Biblioteca Pública Menezes Pimentel, 1914.

Mensagem da Assembléia (1918). Fortaleza: Setor da Hemeroteca da Biblioteca Pública Menezes Pimentel, 1918.

Relatório Governo do Estado do Ceará - Tomaz Pompeu (1919). Fortaleza: Hemeroteca da Biblioteca Pública Menezes Pimentel, 1919.

CUNHA, Cecília. Uma escritora feminista: fragmentos de uma vida. Revista Estudos Feministas, Florianópolis, v. 16, n. 1, p. 271-276, 2008.

FIALHO, Lia Machado Fiuza; SÁ, Évila Cristina Vasconcelos de. Interfaces entre a obra "Canções da Escola" e o Ensino Primário Cearense. In: STAMATTO, Maria Inês Sucupira; NETA, Olivia Morais de Medeiros (Orgs.). Histórias de ensinos no Brasil. João Pessoa: Ideia, 2016. p. 25-44.

FOUCAULT, Michel. Vigiar e punir: nascimento da prisão. Petrópolis: Vozes, 1986.

GALENO, Henriqueta. Henriqueta Galeno no Congresso Internacional Feminino, na Academia Carioca de Letras e no Centro Cearense. Fortaleza: Urania, 1932.

Mulheres admiráveis. Fortaleza: Henriqueta Galeno, 1965.

GIRÃO, Raimundo. Geografia estética de Fortaleza. 2 ed. Fortaleza: UFC, 1979. JORNAL CORREIO DO CEARÁ. Sepultada hoje a grande animadora das Letras do Ceará: Henriqueta Galeno. Jornal Correio do Ceará, Fortaleza, CE, 11 set. 1964. Hemeroteca do Centro Nacional de Folclore e Cultura Popular - Iphan. Disponível em:<http://docvirt.com/docreader.net/Docreader.aspx?bib=tematico\&pagfis=2993>. Acesso em: 10 jul. 2017.

JORNAL GAZETA DE NOTÍCIAS. Jornal Gazeta de Notícias (1931). Retirado do livro "Henriqueta no Congresso Feminino, na Academia Carioca de Letras, no Centro Cearense". Biblioteca da Casa de Juvenal Galeno. Fortaleza-CE. p. 81.

LE GOFF, Jacques. São Francisco de Assis. 9 ed. Rio de Janeiro: Record, 2010a.

São Luís. 4 ed. Rio de Janeiro: Record, 2010b.

LEVI, Giovanni. Usos da biografia. In: AMADO, Janaína; FERREIRA, Marieta de Moraes (Orgs.). Usos \& abusos da história oral. Rio de Janeiro: FGV, 1996. p. 167-182.

LORIGA, Sabina. O pequeno x: da biografia à história. Belo Horizonte: Autêntica, 2011. MACHADO, Charliton José dos Santos. Zilda da Costa Mamede (1928-1985): passos de uma pesquisa biográfica. In: VASCONCELOS, José Geraldo et al. (Orgs.). Tempo, espaço e memória da educação: pressupostos teóricos, metodológicos e seus objetos de estudo. Fortaleza: UFC, 2010. p. 114-126.

MALUF, Marina; MOTT, Maria Lúcia. Recônditos do mundo feminino. In: SEVCENKO, Nicolau (Org.). História da vida privada no Brasil República: da belle époque à era do rádio. São Paulo: Companhia das Letras, 1998. p. 367-421. v. 3.

OLIVEIRA, Iranilson Buriti de. Façamos a família à nossa imagem: a construção de conceitos de família no Recife moderno (décadas de 1920 e 1930). 2002. 348 f. Tese (Doutorado em História) - Programa de Pós-Graduação em História, Universidade Federal de Pernambuco, Recife, 2002.

OLIVEIRA, Joyce Carneiro de. Entre a guerra e as reformas: o ensino secundário 
cearense (1918-1930). 2007. 124 f. Dissertação (Mestrado em Educação) - Programa de Pós-Graduação em Educação Brasileira, Universidade Federal do Ceará, Fortaleza, 2007. PONTE, Sebastião Rogério. Fortaleza belle époque: reformas urbanas e controle social (1860-1930). 3 ed. Fortaleza: Demócrito Rocha, 2001.

REIS, José Carlos. Escola dos Annales: a inovação em história. São Paulo: Paz e Terra, 2000.

RODRIGUES, Rui Martinho. Biografia e gênero. In: FIALHO, Lia Machado Fiuza et al. (Orgs.). Biografia de mulheres. Fortaleza: EdUECE, 2015.

SÁ, Adísia. Henriqueta Galeno. In: VV.AA (Org.). Mulheres do Brasil. Fortaleza: Henriqueta Galeno, 1971.

SÁ, Évila Cristina Vasconcelos; FIALHO, Lia Machado Fiuza. Biografias de Alba Valdéz e Henriqueta Galeno; primeiras educadoras a ingressarem na Academia Cearense de Letras (1874-1964). In: DE CARVALHO, Maria Vilani Cosme; CARVALHÊDO, Josania Lima Portela (Orgs.). Fundamentos da educação. Teresina: UFPI, 2016. p. 1-10.

SILVA JÚNIOR, Roberto da; RODRIGUES, Washington Luís. Educação, ciência e política na biografia de Berta Lutz. In: FIALHO, Lia Machado et al. (Orgs.). Biografia de mulheres. Fortaleza: UECE, 2015. p. 108-121.

SILVA, Alexandra Lima da. Lado a lado: marcas católicas do bandeirantismo no Brasil.

História da Educação, Porto Alegre, v. 21, n. 52, p. 21-39, 2017.

SOIHET, Rachel. A pedagogia da conquista do espaço público pelas mulheres e a militância feminista de Berta Lutz. Revista Brasileira de Educação, Rio de Janeiro, n. 15, p. 97-117, 2000.

THOMPSON, E. P. A formação da classe operária inglesa. 4 ed. Rio de Janeiro: Paz e Terra, 2004.

VITOR, Hugo. O Liceu do Ceará em cem anos. Fortaleza: Iracema, 1945.

LIA MACHADO FIUZA FIALHO é professora do Centro de Educação e do Programa de PósGraduação em Educação na Universidade Estadual do Ceará (Uece), Pós-doutora em Educação (UFPB), Doutora em Educação Brasileira pela Universidade Federal do Ceará (UFC). Editora da Revista Educação \& Formação.

Endereço: Rua Aluísio Soriano Aderaldo, 50 - ap. 1402, Cocó, 60192-330, Fortaleza/CE, Brasil.

E-mail: lia_fialho@yahoo.com.br

ÉVILA CRISTINA VASCONCELOS DE SÁ é Mestre em Educação pela Universidade Estadual do Ceará (Uece).

Endereço: Rua Manuel Nunes, 54 altos, Antônio Bezerra, 60356-835, Fortaleza/CE, Brasil.

E-mail: evilacrislive@hotmail.com 
Recebido em 22 de julho de 2017.

Aceito em 03 de maio de 2018.

(c) (i) 